О.П. Мусієнко, І.М. Тупиця, М.В. Пархоменко, В.Д. Коломієць, Б.І. Бойко

Харківський національний університет Повітряних Сил ім. І. Кожедуба, Харків

\title{
РОЗРОБКА ІМІТАЦІЙНОЇ МОДЕЛІ ОЦІНКИ МЕТОДУ ЗАХИСТУ КАНАЛІВ КОМАНДНО-ТЕЛЕМЕТРИЧНОЇ ІНФОРМАЦІЇ ВІД ІНФОРМАЦІЙНОЇ ПРОТИДІЇ ПРОТИВНИКА
}

Розроблена імітаційна модель на основі технологї ортогонального розподілення каналів з мультиплексуванням, щчо призначена для оцінки перешкодозахищеності, а також імітозахисту каналу команднотелеметричної інформації безпілотного літального апарату. Досліджено, щзо існуюча бортова система захисту інформації є морально та технічно застарілою. При иъьому, оцінка захисту каналу зв'язку є недостатньо ефективною для попередження інформаційної протидії противника. Тому запропоновано новий алгоритм імітаційної моделі системи оцінювання захисту каналу зв'язку безпілотного апарату, щзо забезпечить вчасне виявлення та протидію засобам радіоелектронної боротьби противника.

Ключові слова: інформаційна протидія, імітаційна модель, захист інформації, канал зв'язку, безпілотний літальний апарат.

\section{Вступ}

Постановка проблеми. Сьогодні сучасний характер ведення війни диктує провідним державам світу використовувати більш новітні зразки озброєння та військової техніки. Аналіз військових конфліктів, що виникли в таких країнах як Афганістан, Ірак, Лівія, Сирія, а також сьогоднішня ситуація на сході України показала, що в першу чергу виникає суттєва потреба в отриманні своєчасних і достовірних даних, як про свої сили (засоби), так і про протиборчу сторону супротивника. Тут, одним із затребуваних зразків військової техніки, що забезпечує постійний аеромоніторинг місцевості $є$ безпілотні літальні комплекси та апарати (БПЛА) [1-5].

Однак, незважаючи на перспективність використання БПЛА, існує ряд недоліків [3-7]:

- продовжується експлуатація технічно застарілих зразків - комплекси БПЛА військового призначення радянського виробництва (розробка початку 70-х років: комплекс ВР-2 “Стриж” з БПЛА Ту141, комплекс ВР-3 “Рейс” з БПЛА Ту 143);

- істотною $є$ проблема забезпечення передачі інформації по каналах зв'язку між БПЛА та наземним комплексом у реальному масштабі часу із заданою швидкістю, на визначеній відстані і без спотворення даних в умовах штучного та природного радіоелектронного подавлення;

- велике радіолокаційне поле та плями від БПЛА, що дозволяє вразити його з різних вогневих засобів;

- неправильний вибір оптико-електронних засобів реєстрації зображень перед вильотом БПЛА, що призводить до неякісних знімків (погодні умови, різна освітленість місцевості в різний час доби та ін.).

Але на сьогодні БПЛА все ж таки залишаються найбільш використовуємим засобом аеромоніторингу. Із зростанням значимості використання безпілотного літального апарату зростає актуальність проблеми захисту каналів командно-телеметричної інформації БПЛА. Це в свою чергу впливає на якість та оперативність отримання розвідувальної інформації.

Отже, пропонується розробити імітаційну модель оцінки методу захисту каналів команднотелеметричної інформації в умовах інформаційної протидії противника.

Аналіз останніх досліджень і публікацій. Аналіз останніх наукових публікації [8-12] свідчить про те, що існує багато методів оцінювання спотворень OFDM-сигналів. У середовищі розповсюдження сигнали розрізняються за порядком розміщення опорних сигналів і способом інтерполяції оцінок на інформаційні символи. При цьому існує безліч модифікацій цих методів.

Перелік вибірки методів досліджень дуже різноманітний, але в цій вибірці багато методів, які є досить складними для оцінки точності та достовірності даних моделей. Тому, порівняльний аналіз чутливості розроблених алгоритмів проводився шляхом зіставлення результатів моделювання 3 показниками методів, а саме:

- оцінка каналу по розподіленим опорним сигналам методом найменших квадратів 3 лінійною інтерполяцією в часі;

- оцінка каналу по розподіленим опорним сигналам на основі оптимального фільтра Вінера.

Метою статті $\epsilon$ розробка імітаційної моделі системи управління безпілотним літальним апара- 
том для оцінки перешкодозахищеності, а також імітозахисту каналу командно-телеметричної інформації безпілотного літального апарату.

\section{Виклад основного матеріалу}

Головним чином дослідження та розробка алгоритму імітаційної моделі має на меті підвищити точність оцінювання захисту каналу передачі даних в умовах, що висуває сучасність.

Для побудови імітаційної моделі було використане програмне забезпечення середовища MATLAB. Ця програма дозволила обробити отримані результати та успішно провести імітаційне моделювання процесів в системі. Далі пропонується більш детально дослідити методику моделювання моделі.

Так методика дослідження складається 3 трьох етапів. Перший етап - отримання часової реалізації процесу на вході системи. Другий етап включає в себе наступні складові: обробку часової реалізації за допомогою розглянутих в роботі алгоритмів; отримання реалізацій сигналів усередині системи та на їі виході. На третьому етапі виконується обробка результатів отриманих реалізацій для визначення оцінок робочих характеристик.

Необхідно відзначити, що реалізація каналу зв'язку є випадкова в силу непостійності часу запізнювання променів та їх ослаблення. У більшості розглянутих випадків технічно можливе формування та обробка реалізацій сигналу довжиною, що значно перевищує час когерентності каналу поширення. Це дозволить отримувати оцінки характеристик шляхом усереднення по одній реалізації. В інших випадках для їх отримання виконується усереднення оцінок, отриманих для декількох реалізацій.

Для кількісної оцінки результатів застосування алгоритмів оцінювання параметрів каналів була розроблена імітаційна модель системи зв'язку з використанням OFDM в програмному пакеті MATLAB. Програмна модель та іiі структурна схема представлена на рис. 1.

Структурна схема імітаційної моделі, що представлена на рис. 1 свідчить про те, що вона повторює загальну схему системи передачі OFDMсигналів 3 додаванням службових блоків. Функція формування сигналу “OFDM_signal_gen” виконує перерахунок вхідних параметрів: щільності розміщення опорних сигналів, кількості частотних позицій виділених для їх передачі та схеми їх розміщення відносної довжини захисного інтервалу (3I), розміру сигнальної системи $M$, числа символів в реалізації $K_{S}$.

До основних параметрів OFDM-сигналу входять наступні: число використовуваних несучих, число несучих з даними $N_{\text {Д}}$, розмір використовуваного ДПФ. Перед тим як згенерувати дані параме- три в системі, задаються потрібні для неї еталоні значення для реалізації системи. Далі генерується реалізація псевдовипадкових переданих даних у вигляді масиву цілих чисел від 0 до $2^{\mathrm{M}-1}$ розміром $N_{д} \times K_{S}$. Об'єкт QАМ-модулятора кожному елеме-

нту цього масиву ставить у відповідність комплексну амплітуду несучих. Після отримання значень комплексних амплітуд несучих виконується розміщення інформаційних сигналів і опорних сигналів 3 псевдовипадковою двійковою фазовою модуляцією в частотно-часовій сітці.

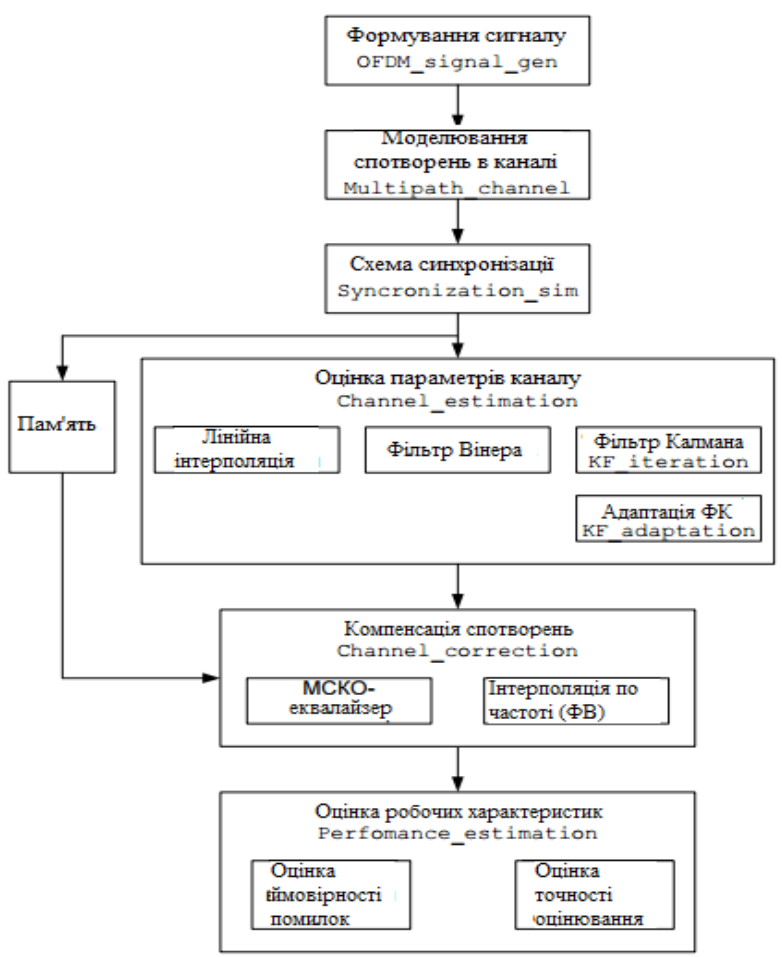

Рис. 1. Структурна схема імітаційної моделі Джерело: розроблено авторами.

Потім за допомогою операції зворотнього дискретного перетворення Фур'є (ЗДПФ) формується масив векторів дискретних відліків OFDM-сигналу у часовій області. Згенерована послідовність частот формується на основі вищезазначених даних. Додавання 3І виконується шляхом операції конкатенації, а підсумкова реалізація OFDM-сигналу - шляхом реорганізації елементів отриманого масиву.

Для моделювання спотворень сигналу в каналі функцією "Multipath_channel” задаються наступні параметри: період дискретизації сигналу, максимальне доплерівське зрушення, фактор Райса, тип модельованого каналу поширення.

Залежно від заданого типу каналу обирається число променів поширення. Далі для кожного з них генерується випадкова реалізація змінного в часі комплексного коефіцієнта посилення із заданими спектральними властивостями. При моделюванні ряду варіантів поширення сигналу необхідно фор- 
мування сигналів, які не передбачені стандартними інструментами MATLAB. Тому для вирішення цього завдання була написана функція, яка використовує наближений метод формування сигналів в частотній області:

$$
x(n)=\operatorname{IDFT}\{X(k)\}=\sum_{k=0}^{N-1} X(k) e^{j(2 \pi k n / N)},
$$

де $\operatorname{IDFT}\{X(k)\}$ - зворотнє дискретне перетворення Фyp'є;

$X(k)$ - комплексний модулюючий символ, $X(k)=|X(k)| \times \exp (j \varphi(k)) ;$

$N$ - число піднесучих коливань, формуючих один OFDM символ.

Функція синхронізації "Synchronization Sim" призначена для імітації процесів, що відбуваються при частотної і часової синхронізації. При цьому час початку символів вважається відомим і часова синхронізація зводиться до розбиття прийнятого сигналу на відрізки довжиною $N_{S}$ з відкиданням 3І. Імітація дії схеми частотної синхронізації полягає в частотному зсуві сигналу на виході каналу таким чином, щоб кореляція передавальних коефіцієнтів двох сусідніх символом мала нульовий аргумент.

Оцінювання викривлення сигналу в каналі виконується функцією “Channel Estimation”. При цьому в ній реалізований запропонований алгоритм на основі фільтру Калмана (ФК) - функції "KF_iteration" та "KF-adaptation", а також алгоритми на основі фільтру Вінера (ФВ) та лінійної інтерполяції. Функція "Channel_correction” виконує компенсацію викривлень в каналі. При цьому для інтерполяції отриманих оцінок частотних характеристик (ЧХ) по частоті використовується фільтр Вінера i вектор оцінок, отриманих за допомогою масиву фільтрів Калмана.

3 метою перевірки основних результатів досліджень пропонується використовувати програмноапаратний стенд (ПАС), представлений на рис. 2. До складу стенду входять персональний комп'ютер (ПК) та обчислювальний модуль Xilinx KC705, в якому реалізовані запропоновані алгоритми оцінювання.

Програмна частина макету реалізована на ПК та складається з трьох основних частин: модуля формування сигналу (МФС), модуля аналізу результатів обробки (МАР) та модуля передачі і прийому інформації (МППІ). Модуль передачі і прийоми інформації є окремою програмою для операційної системи Windows 7, що реалізує передачу та прийом даних по протоколу UDP інтерфейсу Ethernet.

Апаратна частина макету реалізована на обчислювальному модулі Xilinx KC705, ядром якого $є$ програмована логічна інтегральна схема (ПЛІС) Kintex 7 XC7К325Т, а для зв'язку з ПК використовується інтегральна мікросхема (IMC) фізичного рівня
Ethernet.

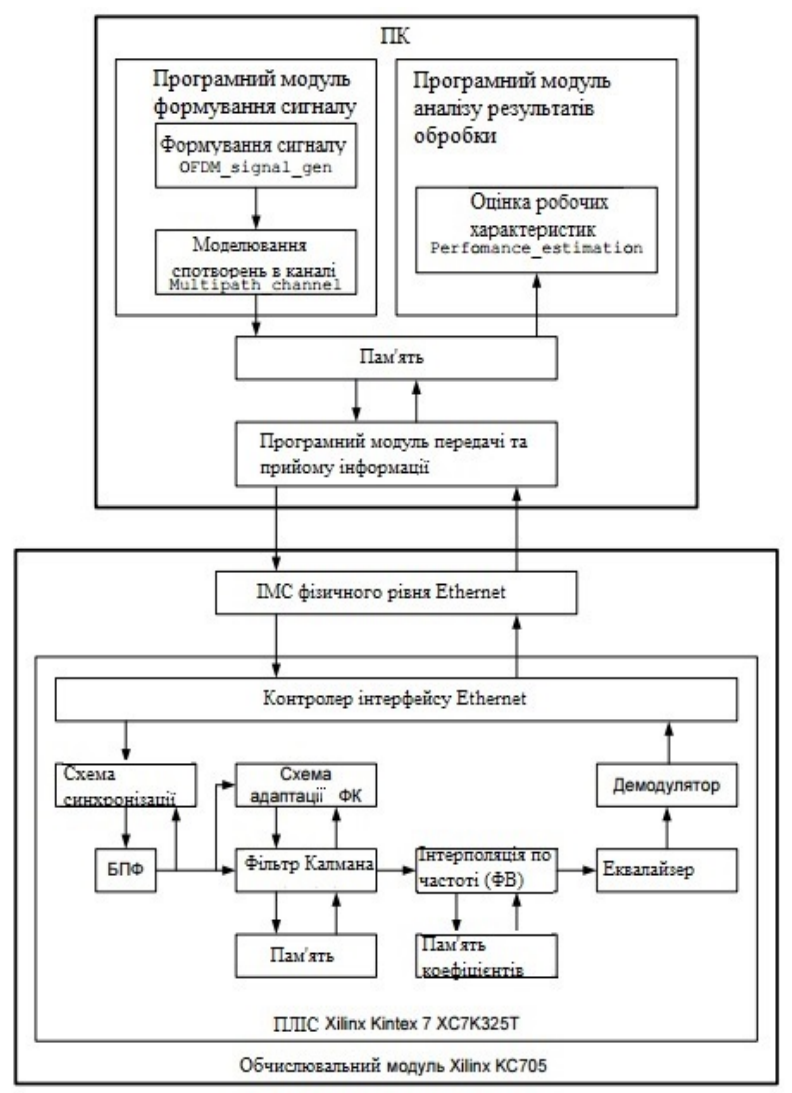

Рис. 2. Блок-схема програмно-апаратного стенду Джерело: розроблено авторами.

МФС виконує формування реалізації сигналу на виході каналу поширення та зберігає іiі у вигляді файлу на жорсткому диску ПК. Цей файл за допомогою МППІ передається в обчислювальний модуль, де виконується його обробка (синхронізація, виділення комплексних амплітуд несучих та оцінка спотворень в каналі за допомогою запропонованих в роботі алгоритмів компенсації спотворень, і демодуляція сигналу). Отримані в результаті обробки оцінки переданих цифрових даних та оцінки спотворень в каналі передаються в ПК та зберігаються у вигляді реалізації на жорсткому диску. Заключна обробка виконується за допомогою МАР і включає компенсацію спотворень в каналі згідно з отриманими оцінками, демодуляцію сигналу та розрахунок частоти бітових помилок.

Введення оброблюваного сигналу і виведення результатів обробки в ПЛІС виконується по інтерфейсу Ethernet через IMC Marvel 88E1111. Вхідний сигнал являє собою послідовність комплексних чисел. Дійсна та уявна частини представляються у 16бітному форматі з фіксованою комою. Для виконання синхронізації по часу та грубої синхронізації по частоті використовується алгоритм синхронізації по 3I, а для точної частотної синхронізації - алгоритм синхронізації по опорним сигналам в частотній області. 
Адаптація коефіцієнтів фільтра Вінера, що виконує інтерполяцію оцінок ЧХ по частоті виконується по єдиному параметру - відношення сигнал\шум (ВСШ) [5]. Для цього попередньо розраховані коефіцієнти для значень ВСШ 0, 5, .., 35 дБ, і 3 них вибираються ті, які відповідають значенням ВСШ, найбільш близького до оціненого. Для компенсації впливу каналу використаний алгоритм, заснований на LDL-розкладанні передавальної матриці з попередньої віконної обробкою. При використанні оптимального фільтру Вінера для інтерполяції оцінок ЧХ за часом розраховувалися коефіцієнти фільтра. Потім коефіцієнти передавалися в апаратну частину разом з оброблювальним сигналом.

Результати дослідження та кількісна оцінка ефективності даної імітаційної моделі алгоритму наведені на рис. 3.

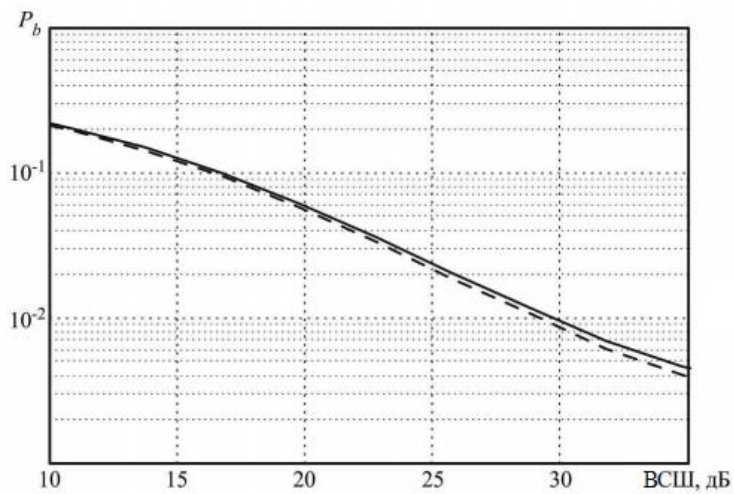

Рис. 3. Оцінки ймовірності бітових помилок Джерело: розроблено авторами.

На рис. 3 представлені суцільними лініями оцінки ймовірності бітових помилок, які отримані експериментально, а штриховими - Оцінки ймовірності бітових помилок, які отримані шляхом імітаційного моделювання.
При обробці сигналу використовується ФК, що заснований на вирішені матричної моделі. Ця операція включає в себе дію скалярного добутку за системою матриць скалярних величин.

Аналіз рис. 3 свідчить про те, що результати отримані експериментальним шляхом, майже співпадають 3 теоретичними результатами. При цьому, кількісна розбіжність, не перевищує 10\%. Розбіжності пояснюються квантуванням сигналу і застосуванням алгоритмів апаратної обробки, що внесено до його сигнального коду, які використовують уявлення даних в форматі з фіксованою комою. Найбільший вплив на процес зменшення ймовірності виникнення помилок вносить точність виконання операції звернення до запропонованого вище алгоритму.

\section{Висновки}

В даній роботі було розроблено ефективну імітаційну модель алгоритму оцінювання захисту OFDM-радіоканалу, що призначений для каналу обміну командно-телеметричною інформацією.

Розроблена модель дозволяє зменшити ймовірність бітової помилки в 4-5 разів.

Також було практично проведено тестування даної моделі та доведено іiі ефективність. На основі проведених досліджень можна зробити висновок, що дана система більш ефективна від існуючої в 3-4 рази, та точніше на 50-60\% в експерементальнодослідно заданих умовах іï використання.

Пропонується використовувати модель, створену на основі алгоритму роботи OFDMрадіоканалу в бортових безпілотних системах авіаційного зв'язку.

\section{Список літератури}

1. Richa B. Impact of Sampling Theorem on Pilot Aided Channel Estimation for OFDM based Multi-Carrier System | B. Richa, S. Shweta // International Conference on Advances in Electronics and Electrical Engineering. - Bangkok, Thailand, 23 June 2012. - P. 19-25. https://doi.org/10.15224/978-981-07-2683-6-104.

2. Haas E. Aeronautical channel modeling / E. Haas // IEEE Transactions on Vehi-cular Technology. - № 2(51), 07 August 2002. - P. 254-264. https://doi.org/10.1109/25.994803.

3. Yong S.C. MIMO-OFDM Wireless Communications with MATLAB / S.C. Yong, K. Jaekwon. - New Jersey: John Wiley \& Sons Ltd, 2010. - 544 p.

4. Sinem C. Channel Estimation Techniques Based on Pilot Arrangement in OFDM Systems / C. Sinem, E. Mustafa, P. Anuj, B. Ahmad // IEEE Transactions on Broadcasting. - 2002. - № 3(48). - P. $223-229$. https://doi.org/10.1109/TBC.2002.804034.

5. Метод підвищення пропускної спроможності скритого каналу в інфокомунікаційних системах спеціального призначення / І.М. Тупиця, В.В. Димчук, К.В. Чуянов, М.М. Кодацький // Системи озброєння і військова техніка. -2019. - № 4(60). - C. 53-57. https://doi.org/10.30748/soivt.2019.60.07.

6. Обгрунтування напрямку підвищення оперативності доставки інформації у автоматизованих системах обробки розвідувальних даних / В.В. Бараннік, О.П. Давикоза, О.П. Мусієнко, Д.А. Тарасенко // Збірник наукових праць Харківського національного університету Повітряних Сил. - 2017. - № 4(53). - С. 71-76.

7. Алімпієв А.М. Застосування досвіду АТО для підготовки фахівців зв'язку, РТЗ та IC / А.М. Алімпієв, O.I. Кушнір, К.С. Васюта та ін. - Х.: ХУПС, 2016. - 328 с.

8. Unmanned Aircraft Systems Roadmap [Electronic resource] / USA: Office of the Secretary of Defense, 2005. - 33 p. Available at: https://www.hsdl.org/?abstract\&did=236553. 
9. The Principles of Developing a Differential Video Controlling Scheme Based on the Use of Intelligent Agents / V. Barannik, N. Barannik, O. Stetsenko, A. Musienko, S. Shulgin, I. Shevchenko // 2019 IEEE International Scientific-Practical Conference Problems of Infocommunications "Science and Technology". - Kyiv, 8-11 October 2019. - P. 877-880. https://doi.org/10.1109/PICST47496.2019.9061244.

10. The Method of Clustering Information Resource Data on the Sign of the Number of Series of Units as a Tool to improve the Statistical Coding Efficiency / V. Barannik, I. Tupitsya, O. Dodukh, V. Barannik, M. Parkhomenko // IEEE 15th International Conference on the Experience of Designing and Application of CAD Systems. - Polyana-Svalyava, 26 February 2 March 2019, P. 32-35. https://doi.org/10.1109/CADSM.2019.8779243.

11. Two-Hierarchical Scheme of Statistical Coding of Information Resource Data with Quantitative Clustering / V. Barannik, I. Tupitsya, I. Gurzhii, S. V. Barannik, Sidchenko, O. Kulitsa // IEEE International Conference on Advanced Trends in Information Theory. - Kyiv, 18-20 December 2019. - P. 89-92, https://doi.org/10.1109/ATIT49449.2019.9030451.

12. The Application of the Internal Restructuring Method of the Information Resource Data According to the Sign of the Number of Series of Units to Improve the Statistical Coding Efficiency / V. Barannik, I. Tupitsya, V. Barannik, S. Shulgin, A. Musienko, R. Kochan, O. Veselska // 10th IEEE International Conference on Intelligent Data Acquisition and Advanced Computing Systems: Technology and Applications. - Metz, 18-21 September 2019. - P. 65-69, https://doi.org/10.1109/IDAACS.2019.8924460.

13. Encoding mode selection in HEVC with the use of noise reduction / O. Stankiewicz, K. Wegner, D. Karwowski, J. Stankowski, K. Klimaszewski, T. Grajek // International Conference on Systems "Signals and Image Processing". - Poznan, 22-24 May 2017, P. 1-6. https://doi.org/10.1109/IWSSIP.2017.7965589.

\section{Відомості про авторів:}

\author{
Мусіснко Олександр Павлович \\ кандидат технічних наук \\ викладач \\ Харківського національного університету \\ Повітряних Сил ім. І. Кожедуба, \\ Харків, Україна \\ https://orcid.org/0000-0002-2441-4609
}

\section{Тупиця Іван Михайлович}

викладач

Харківського національного університету

Повітряних Сил ім. І. Кожедуба,

Харків, Україна

https://orcid.org/0000-0001-6806-4914

\author{
Пархоменко Максим Вікторович \\ викладач \\ Харківського національного університету \\ Повітряних Сил ім. І. Кожедуба, \\ Харків, Україна \\ https://orcid.org/0000-0001-6062-7743
}

\section{Коломієць Василь Дмитрович}

курсант

Харківського національного університету

Повітряних Сил ім. І. Кожедуба,

Харків, Україна

https://orcid.org/0000-0003-4800-3211

\section{Бойко Богдан Ісламович \\ курсант}

Харківського національного університету

Повітряних Сил ім. І. Кожедуба,

Харків, Україна

https://orcid.org/0000-0003-3329-8870

\section{Information about the authors:}

\section{Olexander Musienko}

Candidate of Technical Sciences

Instructor

of Ivan Kozhedub Kharkiv National

Air Force University,

Kharkiv, Ukraine

https://orcid.org/0000-0002-2441-4609

\section{Ivan Tupitsya}

Instructor

of Ivan Kozhedub Kharkiv National

Air Force University,

Kharkiv, Ukraine

https://orcid.org/0000-0001-6806-4914

\section{Maksim Parkhomenko}

Instructor

of Ivan Kozhedub Kharkiv National

Air Force University,

Kharkiv, Ukraine

https://orcid.org/0000-0001-6062-7743

\section{Vasily Kolomiets}

Cadet

of Ivan Kozhedub Kharkiv National

Air Force University,

Kharkiv, Ukraine

https://orcid.org/0000-0003-4800-3211

\section{Bogdan Boyko}

Cadet

of Ivan Kozhedub Kharkiv National

Air Force University,

Kharkiv, Ukraine

https://orcid.org/0000-0003-3329-8870 


\section{РАЗРАБОТКА ИМИТАЦИОННОЙ МОДЕЛИ ОЦЕНКИ МЕТОДА ЗАЩИТЫ КАНАЛОВ КОМАНДНО- ТЕЛЕМЕТРИЧНОЙ ИНФОРМАЦИИ ОТ ИНОФОРМАЦИОННОГО ПРОТИВОДЕЙСТВИЯ ПРОТИВНИКА}

А.П. Мусиенко, И.М. Тупица, М.В. Пархоменко, В.Д. Коломиец, Б.И. Бойко

Разработана имитационная модель на основе технологии ортогонального распределения каналов с мультиплексированием, предназначенная для оценки помехозащищенности, а также имитозащиты канала команднотелеметрической информации беспилотного летательного аппарата. Доказано, что существующая бортовая система зашиты информачии является морально и технически устаревщей. При этом, оценка зашиты канала связи является недостаточно эффективной для предупреждения информационного противодействия противника. Поэтому предложен новый алгоритм имитаџионной модели оценки защиты канала связи беспилотного аппарата, который обеспечивает своевременное выявление и противодействие средствам радиоэлектронной борьбы противника.

Ключевые слова: информационное противодействие, имитаиионная модель, защита информации, канал связи, беспилотный летательный аппарат.

\section{DEVELOPMENT OF A SIMULATION MODEL FOR EVALUATING THE METHOD OF PROTECTING THE CHANNELS OF COMMAND-TELEMETRIC INFORMATION FROM INFORMATION COUNTERMEASURES OF THE ENEMY}

O. Musienko, I. Tupitsya, M. Parkhomenko, V. Kolomiets, B. Boyko

A simulation model has been developed based on the technology of orthogonal channel distribution with multiplexing, designed to assess the noise immunity, as well as the imitation protection of the command-telemetric information channel of an unmanned aerial vehicle. It has been proven that the existing on-board information protection system is morally and technically outdated. At the same time, the assessment of the protection of the communication channel is not effective enough to prevent information countermeasures by the enemy. Therefore, a new algorithm for the simulation model for assessing the protection of the communication channel of an unmanned vehicle is proposed, which ensures timely detection and counteraction to the enemy's electronic warfare. Algorithmic implementation of the proposed model of imitation protection of the command-telemetric information channel of an unmanned aerial vehicle is implemented using the MATLAB software package using Kalman and Wiener filters. Due to the lack of the necessary mechanisms for modulating signals in the frequency domain in the used software product, a mathematical apparatus for generating signals in the frequency domain using the inverse Fourier transform was developed. Also, this model was practically tested and its effectiveness was proved. Based on the studies carried out, it can be concluded that this system is 3-4 times more effective than the existing one, and more precisely by 50-60\% of the experimentally specified conditions of its use. The developed simulation model for assessing the protection of the command-telemetry information exchange channel allows reducing the probability of a bit error by almost 5 times. It is proposed to use a model created on the basis of the OFDM radio channel operation algorithm in onboard unmanned aerial communication systems.

Keywords: information counteraction, simulation model, information security, communication channel, unmanned aerial vehicle. 